\title{
Improving the "Tandusan" Traditional Coconut Oil Processing Process at the Sari Guna Mertha Business Study Group in Carangsari Village, Badung
}

\author{
I Wayan Sudiarta ${ }^{1}$, A.A. Made Semariyani ${ }^{2}$ and I Gusti Ngurah Sugiana ${ }^{3}$ \\ \{sudiartaiwayan67@yahoo.com\}
}

Warmadewa University

\begin{abstract}
The Community Partnership Program in the Training to Improve the "Tandusan" Traditional Coconut Oil Processing Process was conducted at the Sari Guna Mertha Business Study Group, Banjar Telugtug, Carangsari Village, Petang Sub-district, Badung Regency. This study aims to provide appropriate technology for the diversification of agricultural products such as coconut which is widely available in Carangsari Village. The product has the potential to become Tandusan coconut oil for cooking and consumption. In training with direct practice, it provides additional material on entrepreneurship knowledge, business management, sanitation and hygiene, packaging and marketing. Therefore, participants are able to properly manage their businesses. The methods used in implementing this training are face-to-face interviews, counseling and direct practice. The activities were carried out in stages by monitoring and evaluating the activities to guarantee sucess. Firstly, it was carried out by counseling the appropriate technology for processing coconut into tandusan traditional oil, with the manufacturing process modified, and sanitized with proper processing hygiene for adequate business management, marketing and entrepreneurship. At the first meeting, all participants are given a learning module that needs to be understood before the processing technique is carried out, thereby, making it easier to monitor each instruction. Secondly, a direct training/practice on making tandusan coconut oil products is carried out efficiently. Subsequently, evaluation and repetition are conducted until the participants truly master the technology and are able to eaasily make products independently and in groups. Thirdly, regular assistance is provided to motivate newly started businesses. The results showed that the participants have been able to independently manufacture efficient and better quality tandusan coconut oil products that, understand entrepreneurial knowledge and marketing management, thereby, making them economically independent. Furthermore, activities are also documented in the form of photos and videos and published in journal articles.
\end{abstract}

Keywords : Tandusan coconut oil, Entrepreneurship, Appropriate Technology. 


\section{Pendahuluan}

Kelapa (Cocos nucifera L) termasuk jenis tanaman palma yang mempunyai buah berukuran cukup besar. Batang pohon kelapa umumnya berdiri tegak dan tidak bercabang, dan dapat mencapai 10 - 14 meter lebih. Daunnya berpelepah, panjangnya dapat mencapai 3 - 4 meter lebih dengan sirip-sirip lidi yang menopang tiap helaian. Buahnya terbungkus dengan serabut dan batok yang cukup kuat sehingga untuk memperoleh buah kelapa harus dikuliti terlebih dahulu. Kelapa yang sudah besar dan subur dapat menghasilkan 2 - 10 buah kelapa setiap tangkainya (Palungkun, 2004).

Kelapa merupakan tanaman serbaguna karena seluruh bagian tanamannya bermanfaat dalam kehidupan manusia sehari-hari. Pada tahun 2015, luas areal tanaman kelapa di Indonesia mencapai 3,6 juta hektar (Direktorat Jenderal Perkebunan, 2016). Secara keseluruhan luas arealnya mencapai 75.362 ha pada tahun 2015 meliputi luas areal tanaman kelapa dalam 71.916 ha, kelapa hybrida 266 ha, kelapa genjah 3.023 ha, dan kelapa deres 157 ha. Luas areal tanaman kelapa ini mengalami penurunan 2,81 persen dibandingkan tahun 2014 yang mencapai 77.544 ha, yakni untuk jenis kelapa dalam 70.905 ha, kelapa hybrida 266 ha, kelapa genjah 2.760 ha, dan kelapa deres 104 ha (BPS Provinsi Bali, 2016).

Panen buah kelapa dilakukan setelah buah kelapa cukup tua yaitu berumur 12-13 bulan yang ditandai dengan adanya perubahan warna kulit luar kelapa berwarna hijau atau warna coklat kemerahan menjadi berwarna coklat tua. Menurut Suhardiman (1990) tanda dari buah kelapa yang cukup masak adalah sabutnya mulai mengering, tempurungnya sudah berwarna hitam, air buah sudah berkurang (apabila dikocok akan mengeluarkan bunyi) dan berat buah menurun rata-rata $2 \mathrm{~kg}$ pada kelapa dalam, sedangkan kelapa hibrida $1,5 \mathrm{~kg}$ dan jenis kelapa genjah rata-rata $1 \mathrm{~kg}$. Dengan tingginya kandungan gizi buah kelapa maka saat ini kelapa sudah banyak sekali diolah menjadi berbagai produk olahan salah satunya diolah menjadi minyak kelapa yang banyak dibutuhkan untuk untuk pangan dan industri lainnya. Minyak kelapa dapat diolah dengan proses basah maupun kering dan dapat diolah secara tradisional yang dapat menghasilkan minyak dengan kwalitas yang baik. Asam lemak merupakan komponen yang sangat penting dalam molekul minyak. Dalam minyak kelapa kadar asam lemak sekitar 94-98\% dari berat minyak kelapa (Buda, 1981). Minyak kelapa memiliki kandungan asam lemak jenuh yang sangat tinggi, yaitu sekitar 91\% yang terdiri dari kaproat, kaprilat, laurat, miristat, palmitat, stearat, dan arakhidonat. Sedangkan kandungan dari asam lemak yang tidak jenuh sekitar 9\% terdiri dari oleat dan linoleat. Minyak mengandung $84 \%$ trigliserida dengan tiga molekul asam lemak jenuh, $12 \%$ trigliserida dengan dua asam lemak jenuh dan 4\% trigliserida dengan satu asam lemak jenuh (Ketaren, 1986).

Mengingat potensi pasar dan kebutuhan produk olahan kelapa khususnya Minyak Kelapa Tradisional maka diperlukan usaha dan upaya untuk menguasai teknologi pengolahannya sehingga dapat menjadi usaha baru dan dapat menambah penghasilan masyarakat melalui berbagai kegiatan dan wadah yang dapat menghimpun warga dalam bentuk kelompok Belajar Usaha. Kelompok Belajar Usaha (KBU) Sari Guna Mertha yang ada di Banjar Telugtug, Desa Carangsari, Kecamatan Petang, Kabupaten Badung merupakan kelompok Belajar Usaha yang dibentuk oleh mahasiswa Kuliah Kerja Nyata (KKN) yang ditugaskan memotivasi masyarakat dalam bentuk program pemberdayaan masyarakat pada bulan Juli- Agustus tahun 2018 yang lalu secara khusus untuk mengolah buah kelapa yang dihasilkan oleh masyarakat setempat dan kemudian pendampingan dan pembinaan kelompok selanjutnya dilakukan oleh Program Studi Ilmu dan Teknologi Pangan Fakultas Pertanian Universitas Warmadewa mulai tahun 2018 
yang lalu sebagai KBU Binaan dengan produk awalnya berupa Minyak VCO yang sudah mulai dijual dengan merk "Florist". Berdasarkan hasil monitoring dan evaluasi terhadap pelaksanaan kegiatan sebelumnya yang dilakukan bersama mahasiswa KKN Unwar dan Tim Pengabdian Fakultas Pertanian Unwar serta kelihan Dinas Banjar Telugtug kegiatan sebelumnya telah berlangsung dengan sukses. Imbas dari pelaksanaan kegiatan ini ternyata menimbulkan rasa antusias peserta bahkan peserta yang mengikuti melebihi kapasitas dan beberapa peserta telah melanjutkan usaha sendiri secara mandiri. Berkenaan dengan lancarnya kegiatan tersebut dan telah dirasakan imbasnya untuk memotivasi masyarakat dalam merintis usaha kecil maka Ketua Kelompok KBU memohon secara resmi kepada Program Studi Ilmu dan Teknologi Pangan Fakultas Pertanian Universitas Warmadewa agar dilakukan kegiatan pelatihan lanjutan tahap II dengan memilih materi pelatihan dengan tetap berbasis kelapa berupa pembuatan minyak kelapa tandusan. Sebagai salah satu tanaman yang potensial terdapat di desa Carangsari saat ini harga buah kelapa sangat murah bahkan pada saat panen raya harga buah kelapa hanya $\mathrm{Rp} .2000$,- perbuah sedangkan ongkos panjat cukup mahal yaitu Rp.20.000,- perpohon. Dengan murahnya harga buah kelapa yang mereka hasilkan maka muncul pemikiran untuk mengolahnya menjadi minyak sehingga nilai ekonomis buah kelapa dapat lebih ditingkatkan.

Berdasarkan hasil survei dan informasi dari masyarakat di Banjar Telugtug bahwa cara pembuatan minyak kelapa tradisional yang dilakukan kurang efisien dan menghabiskan banyak bahan bakar dan perlu waktu 3 - 4 jam dalam proses pembuatannya karena prosesnya langsung dengan memanaskan santan kelapa. Untuk itu diperlukan sentuhan dunia akademik guna memperbaiki proses pembuatannya. Dengan data ini untuk menekan angka keluarga yang tidak mempunyai pekerjaan tetap terutama ibu-ibu rumah tangga dan dalam rangka persiapan lomba Desa Kabupaten Badung tahun 2019 maka diusulkan kegiatan pengabdian kepada Masyarakat berupa pelatihan pengolahan pangan berbasis kelapa berupa pengolahan Minyak Kelapa Tradisional Tandusan melalui Dana hibah Institusi Universitas Warmadewa tahun 2019 ini.Dengan kegiatan pengabdian kepada masyarakat yang didanai oleh Unwar, diharapkan masyarakat di Banjar Telugtug Desa Carangsari Badung memiliki keterampilan dan wawasan dalam mengelola sumber daya alam setempat serta memiliki jiwa kewirausahaan, sehingga mampu membuka peluang usaha yang berhubungan dengan kondisi wilayah Banjar Telugtug.. Dengan diberikan kegiatan pelatihan teknologi pengolahan minyak kelapa diharapkan masyarakat mampu memproduksi dan memasarkan produk olahannya. Peserta pelatihan dari KBU juga diberikan pengetahuan mengenai manajemen kerja, managemen usaha, strategi pemasaran dan teknik pengemasan sehingga mampu mengatur waktu dan menjalankan usaha dengan sebaik mungkin, dengan demikian mampu meningkatkan pendapatan dan kesejahteraan keluarga.

\section{Metode Pemecahan Masalah}

Metode pelaksanaan kegiatan PKM Pelatihan pengolahan buah kelapa menjadi minyak kelapa Tandusan direncanakan dengan:

1. Metoda diskusi untuk dapat mengetahui permasalahan yang dialami mitra.

2. Metoda tatap muka dan memberikan penyuluhan secara langsung, agar mitra mendapatkan pengetahuan mengenai pengolahan buah kelapa menjadi minyak kelapa 
Tandusan dengan metode pembuatan yang efisien dan irit bahan bakar, kewirausahaan dan managemen usaha.

3. Praktek langsung, yang dipandu oleh instruktur dari kalangan dosen, alumni dan mahasiswa yang telah menempuh mata kuliah Teknologi minyak-lemak, sehingga mitra dapat membuat langsung produk yang diberikan.

\section{Hasil Kegiatan}

Setelah ditanda tanganinya berita acara penggunaan dana $70 \%$ dalam pelaksanaan hibah pengabdian masyarakat Universitas Warmadewa bertempat di Lembaga Pengabdian Masyaraka (LPM) Unwar pada pada hari Senin tanggal 27 Mei 2019 maka segera dilakukan tindak lanjut melakukan pelaksanaan kegiatan sesuai dengan jadwal yang sudah direncanakan dengan tetap mempertimbangkan dan menyesuaikan kegiatan-kegiatan yang sedang dilaksanakan oleh masyarakat di Banjar Telugtug, Desa Carangsari khususnya anggota Kelompok Belajar Usaha (KBU) Sari Guna Mertha yang menjadi mitra dalam PKM ini.

Sebagai tahap awal telah dilakukan pendekatan dan berkoordinasi dengan Kepala Desa Carangsari, kepala lingkungan/Klian Dinas Banjar Telugtug dan ketua KBU untuk mematangkan rencana kegiatan pelatihan yang sudah disepakati saat penjajagan sebelum proposal ini disetujui oleh pihak LPM Unwar. Pertemuan dilakukan pada hari Kamis, 20 Juni 2019 dengan mengambil tempat di rumah salah satu anggota kelompok. Adapun yang diundang antara lain Kepala Desa Carangsari, Kepala Lingkungan / Klian Banjar Telugtug, Ketua serta anggota KBU Sari Guna Mertha. Pada pertemuan tersebut telah disepakati semua anggota KBU ikut dalam Pelatihan Pembuatan Minyak Kelapa Tradisional. Selanjutnya mereka dibagi menjadi 2 kelompok untuk memudahkan dalam praktek pembuatan Tandusan sehingga semuanya bisa mengerjakan dan tahu tahap-tahapan proses pembuatan Tandusan.

Pada hari Selasa, 9 Juli 2019 dilakukan pertemuan dengan semua peserta pelatihan yang dihadiri oleh Kepala Desa, Kepala Lingkungan /Klian Banjar Telugtug, Ketua KBU Sari Guna Mertha serta semua anggota Kelompok. Adapun kegiatan yang dilakukan pada saat itu antara lain :

1. Pembukaan kegiatan pelatihan pengolahan Kelapa menjadi Tandusan oleh Kepala Desa Carangsari selaku pelindung dan penasehat Kelompok Belajar Usaha yang menjadi mitra kegiatan ini

2. Uraian dari Ketua Tim tentang kegiatan Tri Dharma Perguruan Tinggi khususnya kegiatan pengabdian masyarakat Unwar serta rencana kegiatan pelatihan yang akan dilaksanakan sehingga semua peserta dan instruktur yang akan mendampingi selama kegiatan dapat menyamakan persepsi dan kegiatan menjadi lancar.

3. Diskusi dan tanya jawab mengenai permasalahan yang dihadapi mitra, sekaligus merencanakan kegiatan ini yang menunjukan langkah-langkah solusi atas persoalan yang dihadapi.

4. Dilakukan penyerahan peralatan yang akan disumbangkan kepada mitra untuk mendukung pembuatan produk dalam pelatihan dan berproduksi lebih lanjut.

5. Pembagian modul pembelajaran sehingga peserta pelatihan dapat belajar dan mengikuti pelatihan dengan lebih lancar. 
6. Membuat kesepakatan jadwal kegiatan dengan peserta pelatihan sehingga peserta pelatihan dapat mengatur waktu kegiatannya dan kegiaatan dapat berlangsung sesuai rencana dan dari segi waktu dapat efisien dan menyesuaikan dengan aktifitas peserta. Disepakati dalam pertemuan tersebut pelatihan akan dipusatkan di rumah salah satu anggota KBU dan dimulai pada tanggal 20 Juli 2019 .

Pada pertemuan I dilaksanakan kegiatan ceramah sebagai materi penunjang/umum. Untuk kegiatan ini peserta didik diberikan ceramah mengenai :

1. Kebijakan dan Arah Pendidikan Non formal yang diberikan oleh Instruktur Ir. A.A. Made Semariyani, M.Si dan Ir. I Wayan Sudiarta, M.P.

2. Kebijakan dan pentingnya perijinan produk olahan bagi masyarakat yang diberikan oleh Instruktur Ir. A.A. Made Semariyani, M.Si

3. Kewirausahaan, penguatan kelembagaan, kemitraan, kewirausahaan dan pemasaran diberikan oleh Ir. I Gusti Ngurah Sugiana, M.Agb

4. Perlindungan konsumen, sanitasi, higiene, pengemasan dan labelling produk yang diberikan oleh Ir. A.A. Made Semariyani,M.Si

5. Materi khusus berupa : tinjauan tentang kelapa dan prospeknya sebagai bahan baku olahan Tandusan serta nilai gizi dan manfaatnya diberikan oleh Ir. I Wayan Sudiarta,M.P. dibantu oleh Alumni dan Mahasiswa dari Program Studi Ilmu dan Teknologi Pangan Universitas Warmadewa.

Untuk kegiatan ceramah ini panitia menyediakan modul pelatihan yang berisi materimateri dari ceramah di atas serta modul pelatihan pembuatan minyak kelapa tradisional. Dengan cara seperti ini diharapkan peserta didik mendapatkan pemahaman mengenai materi ceramah yang berkaitan dengan kewirausahaan dan memiliki file - file yang sewaktu-waktu dapat diambil jika peserta didik lupa dengan teori dan bahan dari pelatihan. Materi diberikan sedemikian rupa sehingga peserta pelatihan akan terbuka wawasannya dan bersemangat untuk mengukuti pelatihan.

Pada pertemuan ke II diberikan Pelatihan Mengenai Pembuatan Minyak Kelapa Tradisional. Peserta didik dituntun oleh instruktur yang berasal dari Dosen di Program Studi Ilmu dan Teknologi Pangan, Fakultas pertanian, Unwar. Diharapkan peserta didik dapat mengikuti dengan baik, pelatihan yang diberikan. Peserta pelatihan dibimbing oleh instruktur. Pada setiap pertemuan dilakukan evaluasi kegiatan dan monitoring sehingga pada setiap pertemuan kekurangan dan kesalahan dapat dilakukan perbaikan dengan segera pada pertemuan-pertemuan berikutnya.

Pada pertemuan ke III anggota kelompok membuat sendiri Tandusan tanpa dituntun oleh instruktur hasilnya dievaluasi dimana letak kekurangannya agar nantinya diperbaiki pada pertemuan berikutnya. Pada Pertemuan ke IV pelatihan kembali dilakukan dengan memberikan materi yang sama seperti pada pertemuan ke ke III dalam artian kelompok diberikan kebebasan dalam membuat tandusan dan hasilnya dievaluasi kembali untuk mendapatkan tandusan dengan kualitas yang baik.

Produk hasil pelatihan ini kemudian dinilai apakah sudah sesuai dengan hasil akhir produk yang diharapkan yang kemudian menjadi bahan pertimbangan apakah sudah memenuhi 
kriteria untuk mengajukan permohonan untuk mendapatkan ijin produk berupa ijin Produk Industri Rumah tangga (PIRT). Disamping itu diharapkan juga kepada anggota kelompok mencoba membuat sendiri produk yang telah dilatih tersebut dan memasarkannya baik secara manual (dari mulut ke mulut), dan promosi secara on line. Berdasarkan hasil evaluasi yang dilakukan dan berdasarkan hasil diskusi antara instruktur, peserta pelatihan, Ketua kelompok dan Kepala Desa Carangsari maka telah disepakati produk tandusan akan diupayakan untuk dicarikan ijin produk P-IRT sehingga mendapat rekomendasi dari Dinas Kesehatan Kabupaten Badung yang akan dipakai sebagai lampiran permohonan sertifikat penyuluhan keamanan pangan dan sertifikat produksi P-IRT ke Dinas Penanaman Modal dan Pelayanan Terpadu Satu pintu Kabupaten Badung. Pengajuan permohonan ijin P-IRT untuk produk tandusan ini akan dilakukan setelah memenuhi semua persyaratan administrasi yang ditentukan. Harapan kedepannya produk tandusan ini akan menjadi icon Banjar Telugtug, Desa Carangsari Kecamatan Petang, Kabupaten Badung. Disamping itu apabila ijin P-IRT telah terbit, maka pemasaran produk minyak kelapa tradisional bisa menjadi lebih luas tidak saja di pasar tradisional, tetapi juga akan bisa dijual di Toserba, mini Market dan Pasar swalayan karena telah dilengkapi ijin sebagai legalitas produk.

Dari Permasalahan yang dihadapi oleh Mitra/peserta pelatihan maka dapat dirangkum rincian pelaksanaan kegiatan sebagai solusi untuk menyelesaikan permasalahan serta persentase capaian target yang sudah dicapai seperti pada Tabel 1 .

Tabel 1. Capaian target Luaran Kegiatan

\begin{tabular}{|c|c|c|c|c|}
\hline No & Permasalahan & Solusi/Kegiatan & Target Luaran & Capaian target Luaran \\
\hline 1 & $\begin{array}{l}\text { Kelompok yang } \\
\text { tidak aktif }\end{array}$ & $\begin{array}{l}\text { Mengaktifkan kelompok } \\
\text { dengan peremajaan / } \\
\text { pergantian anggota } \\
\text { kelompok }\end{array}$ & 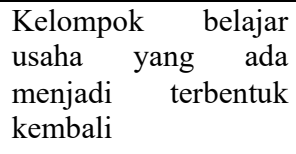 & $\begin{array}{l}\text { Kelompok telah aktif } \\
\text { dan dapat mengikuti } \\
\text { pelatihan }(100 \%)\end{array}$ \\
\hline 2 & $\begin{array}{l}\text { Iptek pengolahan } \\
\text { Minyak Tandusan }\end{array}$ & Ceramah dan pelatihan & $\begin{array}{l}\text { Peningkatan } \\
\text { pemahaman dan } \\
\text { ketrampilan peserta } \\
\text { pelatihan }\end{array}$ & $\begin{array}{l}\text { Telah dilakukan } \\
\text { ceramah, penyuluhan } \\
\text { dan pelatihan }(100 \%)\end{array}$ \\
\hline 3 & $\begin{array}{l}\text { Pengetahuan } \\
\text { kewirausahaan } \\
\text { dan pemasaran } \\
\text { produk }\end{array}$ & Ceramah/penyuluhan & $\begin{array}{l}\text { Peserta memahami } \\
\text { kewirausahaan dan } \\
\text { pemasaran produk }\end{array}$ & $\begin{array}{l}\text { Telah dilakukan } \\
\text { ceramah dan penyuluhan } \\
(100 \%)\end{array}$ \\
\hline 4 & $\begin{array}{l}\text { Sanitasi } \\
\text { higiene }\end{array}$ & Ceramah/penyuluhan & $\begin{array}{lr}\text { Peserta } & \text { pelatihan } \\
\text { memahami } & \text { tentang } \\
\text { pentingnya } & \text { sanitasi } \\
\text { dan higiene } & \end{array}$ & $\begin{array}{l}\text { Telah dilakukan } \\
\text { ceramah dan penyuluhan } \\
(100 \%)\end{array}$ \\
\hline 5 & $\begin{array}{l}\text { Pengemasan dan } \\
\text { labelling }\end{array}$ & Ceramah/penyuluhan & $\begin{array}{lr}\text { Peserta memahami } \\
\text { pentingnya } \\
\text { pengemasan teknik } \\
\text { labelling }\end{array}$ & $\begin{array}{l}\text { Telah dilakukan } \\
\text { ceramah dan penyuluhan } \\
(100 \%)\end{array}$ \\
\hline 6 & Ijin Produk & $\begin{array}{l}\text { Memfasilitasi } \\
\text { permohonan ijin produk }\end{array}$ & $\begin{array}{lr}\text { Produk olahan } & \text { susu } \\
\text { jagung } & \text { manis }\end{array}$ & $\begin{array}{l}\text { Telah mengajukan ijin } \\
\text { P-IRT dan menunggu }\end{array}$ \\
\hline
\end{tabular}




\begin{tabular}{|c|c|c|c|c|}
\hline & & $\begin{array}{l}\text { di Dinas kesehatan } \\
\text { Kabupaten Badung }\end{array}$ & $\begin{array}{l}\text { memiliki ijin produk } \\
\text { PIRT }\end{array}$ & $\begin{array}{l}\text { jadwal untuk diverifikasi } \\
\text { dan uji laboratorium }\end{array}$ \\
\hline 7 & $\begin{array}{l}\text { Peralatan } \\
\text { pengolahan } \\
\text { produk }\end{array}$ & $\begin{array}{lr}\text { Bantuan } & \text { peralatan } \\
\text { penyimpanan } & \text { dan } \\
\text { pengolahan } & \end{array}$ & $\begin{array}{l}\text { Adanya alat-alat } \\
\text { untuk pelatihan dan } \\
\text { untuk berproduksi } \\
\text { selanjutnya }\end{array}$ & $\begin{array}{l}\text { Sudah diberikan bantuan } \\
\text { peralatan }(100 \%)\end{array}$ \\
\hline 8 & $\begin{array}{l}\text { Peningkatan } \\
\text { omzet }\end{array}$ & $\begin{array}{l}\text { Meningkatkan dengan } \\
\text { alternatif produk baru }\end{array}$ & $\begin{array}{l}\text { Jumlah produksi } \\
\text { meningkatkan }\end{array}$ & $\begin{array}{lr}\text { Belum tercapai karena } \\
\text { masih pada tahap } \\
\text { perintisan } \\
\text { pendampingan }\end{array}$ \\
\hline 9 & Publikasi Ilmiah & $\begin{array}{l}\text { Mengupayakan } \\
\text { publikasi pada jurnal } \\
\text { pengabdian masyarakat }\end{array}$ & Terpublikasi & terpublikasi \\
\hline
\end{tabular}

\section{Kesimpulan}

a. Peserta pelatihan telah mengikuti pelatihan dengan semangat dan disiplin terlihat dari daftar kehadirannya.

b. Pelatihan untuk pembuatan produk berupa Minyak Kelapa Tradisional dapat dilaksanakan dengan baik dan peserta pelatihan mampu membuat produk tersebut dengan baik

c. Target luaran dari kegiatan PKM Pelatihan Pembuatan Minyak Kelapa Tradisional ini telah diberikan kepada peserta didik, kecuali untuk memfasilitasi P-IRT dari Dinas Kesehatan Kabupaten Badung masih menunggu jadwal untuk diverifikasi dan uji laboratorium.

Perlu dilakukan pembinaan secara berkesinambungan agar peserta pelatihan dapat melaksanakan kegiatan usaha secara berkelanjutan.

\section{References}

[1] Badan POM. 2003. Higiene dan Sanitasi Pengolahan Pangan. Direktorat Surveylan dan Penyuluhan Keamanan Pangan. Deputi Bidang Pengawasan Keamanan Pangan dan Bahan Berbahaya. Badan Pengawas Obat dan Makanan. Jakarta.

[2] Buckle, K.A., R.A. Edwards, G.H. Fleet dan M. Wootton. 2010. Ilmu Pangan. Penerjemah Purnomo dan Adiono. UI Press. Jakarta.

[3] Buda.1981. Kelapa dan Hasil Olahannya. Bagian Teknologi Pertanian. Fakultas Pertanian Universitas Udayana. Denpasar

[4] Direktorat Jenderal Perkebunan. 2016. Buku Statistika Kelapa (Coconut). Diakses pada ditjenbun.pertanian.go.id/tinymcpuk/gambar/file/statistik/2017/Kelapa-2015-2017.pdf. (diakses 26 Maret 2018).

[5] Ketaren, S dan Djatmiko.1978. Daya Guna Hasil Kelapa. Departemen Teknologi Hasil Pertanian. Fatemeta,IPB. Bogor.

[6] Ketaren, S. 1986. Pengantar Teknologi Minyak dan Lemak Pangan. Cetakan Pertama. Jakarta : UI-Press.

[7] Palungkun, R. 2004. Aneka Produk Olahan Kelapa. Penerbit Swadaya.Bogor. 
[8] Nugroho, S.P. 2010. Karakteristik Usaha Kecil di Indonesia. Perencanaan Pemasaran Usaha Kecil Rumahan. Benefit Jurnal Manajemen dan Bisnis. Vol 14, No 1. 2010. Hal. 22-27 